however, remained histologically healthy in appearance and visual fields would doubtless have showed a pressure atrophy spreading up from the lower field.

\title{
Conclusions
}

Radon therapy for secondary carcinoma of the choroid, in the case described, proved clinically effective over a period of two years and four months. During the major portion of this period good vision was maintained.

Ultimately failure of vision was due to intracranial complications involving pressure on the optic nerve.

Radon may prove to be of value as a curative form of treatment in an otherwise hopeless condition and should be considered as an alternative to enucleation of the eye.

\section{CONGENITAL FAMILIAL CATARACT WITH CHOLESTERIN DEPOSITS}

BY

M. RIAD BEY

CAIRO

THE hereditary factor in many eye diseases has been frequently observed. Of these diseases cataract affords the best example. Nettleship has published details of twenty-two families in which lamellar cataract was found in several generations. The same author and Ogilvie recorded an extraordinary series of discoid postnuclear cataract in a family called Coppock. Hence the name of Coppock cataract was given to it. On the other hand we frequently find isolated crystals embedded in transparent lenses, chiefly in the peripheral part of the lens under the posterior capsule. This condition according to Pellaton is found in 28 per cent. of clear lenses. Cholesterin crystals are not infrequently found in different types of senile, traumatic and complicated cataracts. Burdon Cooper thinks that cholesterin crystals are extremely common in glycosuria, while tyrosin is the commonest crystal to be found in senile forms.

Goulden and other observers have also described the presence of fine crystalline opacities showing green and blue iridescence in thyroid dysfunction, post-operative tetany, Mongolian idiocy and myotonia atrophica. In such cases the crystals are situated chiefly in the anterior and posterior layers of the lens cortex. Doggart reported having seen at Moorfields members of three generations aged twenty years and upwards, in a large family, suffering from 
a peculiar type of slowly progressive cataract, showing numerous blue, green and violet dots situated chiefly in the adult nucleus and the superficial layers of the foetal nucleus. Chow recorded a case of cholesterin crystals with cataract in a student, aged 16 years, distributed in the deep layers of the cortex as well as in the nucleus. The crystals diminished in number towards the periphery.

It seems, however, that the presence of crystals in congenital forms of cataract is very rare.

During the annual meeting of the Ophthalmological Society of Egypt for the year 1935 I reported a case of bilateral congenital cataract associated with numerous crystals grouped towards the axial part of the lens. Owing to the difficulty which exists in obtaining an accurate history from our class of patients, the family history of this case was recorded as negative. In May, 1937, a similar case was discovered at the clinic of the Faculty Hospital which presented the same features. This state of affairs induced me to make further inquiries for a reliable history and it was found that the second patient (No. 7, see chart), was a step-sister to the first (No. 6). Further investigations resulted in the discovery of a most interesting pedigree of familial congenital cataract with deposits of cholesterin crystals. I have succeeded in getting into touch with all available members of this pedigree (see chart).

Patients No. 1, 6, 7, 8 were admitted as in-patients at the Faculty Hospital with a view to further study, while the rest were examined at their homes in Giza, Hawamdieh and Cairo districts.

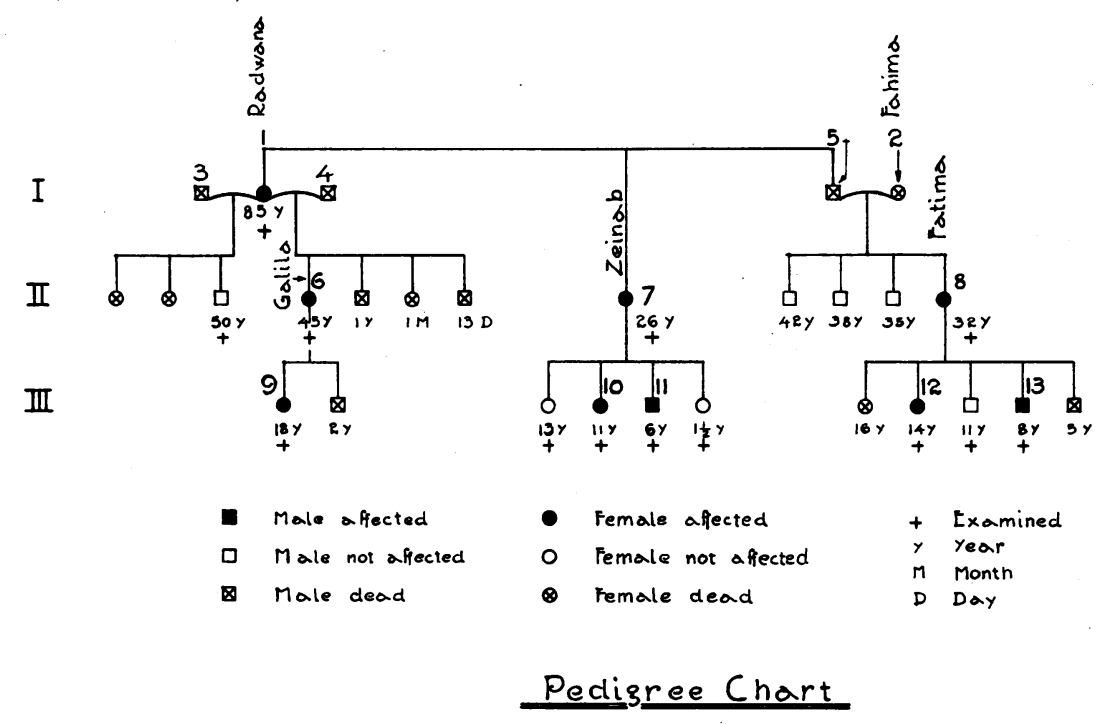




\section{Report on Cases}

Past and present history.-The age of the members examined in this pedigree ranges between 6-85 years. Of the 13 cases examined 7 females and 2 males were affected. There is no history of consanguinity in their parents, nor of mental trouble or convulsions. Two step-sisters $(1,2)$, constitute the material of this report. There is a vague history that their mother complained of some visual defect, most probably cataract. Patient (No. 1) married three times. By her first husband she had three children, one son aged 50 years is still living and not affected. By her second marriage she had four children. The only surviving member, a female (No. 6, the subject of my previous contribution), and her grand-daughter are both affected with this disease. By the third husband, who is at the same time her brother-in-law, being previously married to her step-sister (No. 2), she had one daughter and two grand-children who have inherited this anomaly. Her step-sister (No. 2) had also transmitted this type of cataract to some of her descendents. It is to be observed from the pedigree chart that hereditary influence is strongly marked in the females and that the cataract has been derived from an affected female by continuous descent in three generations.

Investigations.-No constitutional disease was found. No clinical evidence of hypoparathyroidism or hypothyroidism or myotonia atrophica. The presence of cataract and crystal formation was bilateral except in patient (No, 1), who lost her left eye early in childhood probably through purulent ophthalmia. Owing to the similarity of the clinical appearance of the cataract in all the cases examined, one description seems to be quite adequate. With focal examination the cataract appears to be composed of discrete or confluent, nearly circular, opacities of white or grey colour, grouped towards the axial part of the lens in the position occupied by the lines of the lens sutures. They extended in some cases deeply backwards in the lens substance. In other cases the opacities were tube-like in appearance radiating forwards and outwards from the centre. They terminated just short of the lens capsule. Numerous fine shining crystals could be focused scattered in the middle of these opacities. The peripheral part of the lens was quite clear. (See plate.)

The slit-lamp microscope revealed that the space between the anterior capsule and the zone of disjunction was quite clear. In some cases the optical section of a narrow beam localised the opacities and crystals as extending deeply from the anterior cortical zone to the posterior. In others it fell short of the posterior zone of the foetal nucleus. 


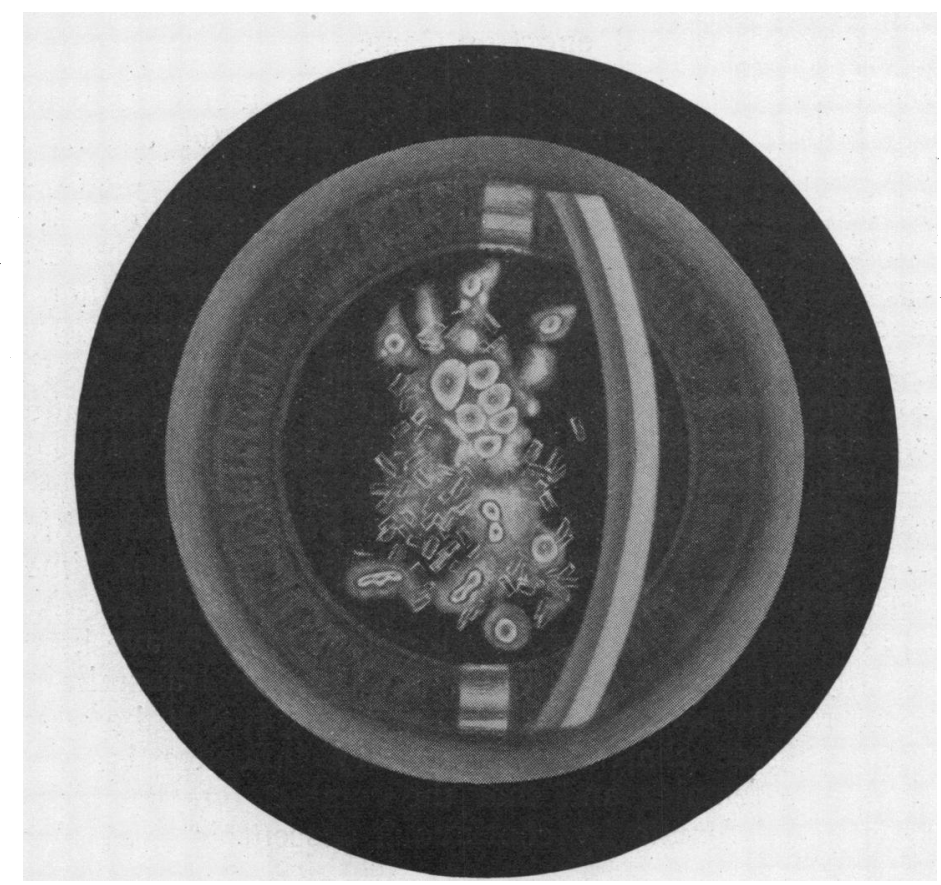

Cataract with cholesterin deposits.

With the broad beam the opacities appeared either as flattened discs more densely opaque at the periphery than at the centre or like a target of grey and white circles. A few others are mulberry-like and look diaphanous when. examined by transillumination.

The iridescent crystals are arranged at different angles and in different planes. A few appear to be embedded in the masses of lens opacities. The crystals looked like tiny broken glass fragments, rectangular in shape with a notch at one corner and curiously transparent. They were optically indistinguishable from cholesterin crystals. Neither the opacities nor the crystals were to be seen in the periphery of the lens, but only in its axial portion.

Ida Mann states that the central embryonic nucleus is formed during the first three months of foetal life. The second nuclear layer is formed from the $3 r d$ to the 8 th month. The next layer is laid down during the last week of foetal life and continues to grow layer after layer till the adult period.

As the opacities in these cases are seen in the central embryonic nucleus, I feel justified in stating that this cataract is congenital in origin. Whatever disturbance caused these opacities to appear 
must have acted early in foetal life and have been gradually increasing till a later period. Moreover the similatity of all the cases and the presence of the anomaly in both eyes indicates that the condition is a developmental one.

It is interesting to mention that the percentage of cholesterol in the blood was found to be diminished. It ranged between 114-118 mgr. per cent.

A survey of the available literature show's that no similar pedigree has been reported. No description of such a condition has been recorded in the recent publication of Vogt's atlas, Meesman's or Koby's books on the slit-lamp.

\section{REFERENCES}

NetTleship.-Roy. Lond. Opthal. Hosp. Reps., Vol. XVI, 1905.

NetTleshiP and Ogilvie.-Trans. Ophthal. Soc. U.K., 1906.

Pellaton.-Koby, Slit-lamp. Second edition. Pp. 252. 1930.

BUR DON CQOPER.-Ophthal. Rev., pp. 129-140, 1914.

Goulden.-Trans. Ophthal. Soc.U.K., pp. 97-106, 1928.

DogGaRT.-Ibid., pp. 302-316, 1933.

CHow.-Chinese Med. Jl., September, 1934.

RIAD,-Bull. Ophthal. Soc., Egypt, 1935.

MAN IDA.-Embryology of the Eye.

\section{ANNOTATION}

\section{The Problem of the Partially Sighted}

The problem of the partially sighted is always a difficult one What standard is fair to all concerned in assessing blindness?

A paper by Sir James Barrett in the Medical Journal of Australia of August 13,1938, deals with this subject. He states that the Royal Victorian Institute for the Blind has, as a matter of abstract justice, paid inmates the difference between what they earn and the basic wage. As he says, "the intention was admirable, but unfortunately human nature has as usual asserted itself, and many people who are not blind have pressed for admittance, evidently seeking a secure position and defined wages. With any slackness the institute would have been overwhelmed and rendered insolvent."

The standard of blindness adopted is that of the British Government. Those unable to count fingers at a range of one metre are "blind"; those with vision up to $3 / 60$, are partially sighted ; those with vision between $3 / 60$ and $6 / 60$ are considered in association with the other evidence, such as constricted fields, nystagmus, etc. Patients with vision of better than $6 / 60$ are sometimes admitted to the institute, e.g., cases of retinitis pigmentosa with tubular vision, or cases where blindness is inevitable fairly soon. 